\title{
What Kind of Statetegic Policy for a Better Taking Care of Tuberculosis in Senegal
}

Faye Abdoulaye ${ }^{1 *}$, Bop $\mathrm{M}^{2}$, Kane $\mathrm{A}^{2}$ and Diouf $\mathrm{M}^{2}$

${ }^{1}$ Bambey University, Faculty Health and Sustainable Development, Senegal

${ }^{2}$ Ministry of Health and Social Action, Senegal

\begin{abstract}
Tuberculosis constitutes in the developing countries an endemic disease which affects above all the most vulnerable social strata. In Senegal, tuberculosis is a long time fought against and checked by health authorities of the country thanks to a national program against this disease. It has another outbreak as in the majority of south countries because of the infection VIH/AIDS. The necessity is essential towards all levels to intensify and to boost the effective strategies way of fighting in order to check this devastating disease for the families and communities.
\end{abstract}

Keywords: Tuberculosis; Disease; Strategic Fight, Senegal

\section{Introduction}

Paradoxically, the fact that TB can be treated and prevented, in the world in 2011, 8.7 million people developed the disease and 1.4 million died [1]. Similarly, nearly one third of the world's population is currently infected with latent TB, which means that people have been infected with the TB bacteria but have not (yet) developed the disease [1]. Tuberculosis is present everywhere in the world. However, over $95 \%$ of cases and deaths from TB occur in low-and middle-income countries. However, sub-Saharan Africa has the largest proportion of new cases per capita, with more than 260 cases per 100,000 inhabitants in 2011 [2].

In Senegal, tuberculosis is a public health problem. On average, 7,000 new cases of the contagious form of the disease are diagnosed each year by health authorities $[3,4]$. The national program against tuberculosis (NTP) is the response of the Government of Senegal to the pandemic, despite the progress made since its inception, is still not achieved some of its objectives especially the detection rate at $75 \%$. Indeed, in 2011, the rate was estimated at 55\% [5].

HIV infection, due to the immunosuppressant that leads, nowadays constitutes an aggravating factor of endemic tuberculosis. Tuberculosis remains a huge burden to human health, even in the early 21 st century. The situation is deteriorating in many countries, particularly because of the synergy with the HIV epidemic and the emergence of multidrug-resistant (MDR) and extensively drug resistant (XDR) tuberculosis. The urgent development of new tools that can improve the diagnosis, prevention and/or treatment of tuberculosis and other major mycobacterium diseases depends largely on the progress of basic and applied research. Faced with this situation, there is an urgent need for effective strategies and actions to permanently solve the problem of this endemic disease whose impact is too negative on people's lives.

\section{Objective and Methodology}

Thus we will try in the course of our work, after a literature review focused on tuberculosis (national reports, dissertations, research) submit, as part of our plan below Program Fight against Tuberculosis (first part), before then see the difficulties encountered (Part 2), and finally propose strategic directions to follow (Part 3).

\section{Results and Discussion}

\section{The National Program of Tuberculosis (Ntp):}

In Senegal, thousands of new TB cases are detected each year $[3,4]$.
With the detection rate is low probably thousands more cases continue to infect people. Tuberculosis is a real public health problem due to its failure by the majority of the population and the persistence of stigma, raising the problem of controlling TB infection. Add to this the constraints and challenges of co-infection TB/HIV and multidrug resistance. The distribution of cases a clear distinction between geographically large urban areas that are much more affected than rural areas [5-7].

From the epidemiological point of view the age from 15 to 35 years is much more affected with more than half of the cases and a predominance of men over women $[7,8]$. Other inequalities are also noted in the distribution of this disease, it is encountered in some vulnerable groups such as people living with HIV, prisoners ... He adds that most TB cases are often diagnosed at an late stage in the same statistics with more than half of the patients diagnosed with sputum positive $3+$ [7] AFB. As follow-up of patients huge efforts have been made over the last decade, increasing the rate of patients under treatment lost to $25 \%$ in 2001 to $5 \%$ in 2010 [3]. It remains to maintain these efforts to further reduce this rate.

The NTP is designed to reduce the morbidity and mortality associated with tuberculosis. The NTP has set an overall target to control tuberculosis endemic throughout the country and minimize the development of resistance of the bacillus to drugs.

However, he wants a practical way to cure at least $85 \%$ of TB cases detected positive smears.

The NTP's has as main specific objectives:

- Ensuring the training, retraining and supervision of staff (doctors, pharmacists, nurses, educators, microscopists, etc).

- Establish operational unit's diagnostic cases by microscopy.

*Corresponding author: Faye Abdoulaye, Bambey University, Faculty Health and Sustainable Development, Senegal, Tel: 221775611946; E-mail: abfayecr@hotmail.com

Received July 19, 2013; Accepted August 12, 2013; Published August 14, 2013

Citation: Abdoulaye F, Bop M, Kane A, Diouf M (2013) What Kind of Statetegic Policy for a Better Taking Care of Tuberculosis in Senegal. J Trop Dis 1: 112 doi:10.4172/2329-891X.1000112

Copyright: (c) 2013 Abdoulaye F, et al. This is an open-access article distributed under the terms of the Creative Commons Attribution License, which permits unrestricted use, distribution, and reproduction in any medium, provided the original author and source are credited. 
- Expand gradually-all treatment centers the short-course chemotherapy under direct observation.

- Provide oversight of primary resistance of Mycobacterium tuberculosis (BK) to TB.

- Strengthen the supply system of essential anti tuberculosis drugs, equipment and laboratory products and management tools.

- Maintain an efficient information system for performance evaluation of screening and treatment.

- Provide information and education for patients, their families and the general population.

\section{The Difficulties of Care}

As a first issue, it should be noted the failure in communication about the disease. Because it is still unknown especially in rural areas. The area where malaria continues dominant disorder that is the primary concern of households.

The time between the onset of the disease and the diagnosis is still long, thereby increasing the risk of spread of the disease. Moreover, vaccination problem especially in rural areas where access to structures remains difficult. Testing needs to be improved for a better form of struggle means testing that are laboratory radio are available in urban areas. Difficulties in diagnosis and treatment of forms of extra pulmonary localization are not negligible. Funding from the government are sometimes insufficient for the acquisition of drugs, diagnostic tools and communication.

People's behavior at home against patients with tuberculosis is a risk factor in the spread of the disease. For patients who often come from rural areas are often housed in small rooms usually occupied by children where the ventilation and lighting are lacking thus creating an environment conducive to the spread of the disease conditions.

\section{Strategic}

Recent years have noted an awareness campaign through the media NTP on risk behaviors in relation to the prevention and treatment of disease. This should be expanded by more accessible communications channels and code to reach the entire population. Training of health personnel especially in the diagnosis of extra-pulmonary forms is also important for early implementation of treatment. Diagnostic equipment: radiology, sputum (AFB) should be available at all levels of prevention center with well-trained staff for handling. Vaccination is a critical element in the fight against any disease. BCG is used against tuberculosis should be made available to staff health and sustainable manner to the most remote areas of the country. Cold chain for the proper conservation should be respected. The constant availability of medicines is also a guarantee of effectiveness in the fight against tuberculosis. It is the same for the proper management of side effects that often lead outright discontinuation.

The directly observed treatment (DOT) undertaken by the NTP is effective and should be provided by the service provider in question and not the coach who sometimes forgets treatment. If not outright create a team of community relay that to observe directly the actual taking of drugs. The change in risk behavior is also mentioned. This change also applies well in populations than among providers. People should be educated on the dangers of cough fever greater than fifteen (15) days with weight loss. This would allow them to show up on time with the claimant. In cases of pulmonary tuberculosis inform the patient of measures to contain the disease. Epidemiological surveillance allows proper monitoring of the disease. The central system (NTP) must receive all information from the device management tools (TB register health center map TB patient register tuberculosis station health. Laboratory for tuberculosis registry etc.) for better coordination. The term evaluations of treatment outcomes are relevant. Because when you treat a disease, it is necessary to ensure his recovery. Not only is the treatment to be completed but with negative smears at two consecutive sputum examinations at the end of the fifth and seventh month or later.

The state must increase its financial contributions to the care of TB patients since they tend to increase in the suburbs and rural areas, among the most vulnerable populations [8-13].

\section{Conclusion}

The Ministry of Health and Social Welfare considers TB control as a priority in its National Health Development Plan (PNDS). The methods of single combat, standardized, easy to apply and easy to evaluate in clinical practice, it is now possible to cure patients suffering from this deadly disease. In recent years, the National Program for the Fight against Tuberculosis has achieved significant results (such as access to diagnosis and treatment throughout the territory) with the support of development partners and efforts considerable Ministry of Health and Social Action.

However, it is understood that the objectives of reducing morbidity and mortality set depends on the commitment of the actors of Health but also the support of the media. Indeed, their involvement in education and information activities of the people is a definite contribution. In addition, adequate staff's training, on the one hand, an effective system of Health, on the other hand is the requirements for an effective fight.

\section{References}

1. Organisation Mondiale de la Santé (2013) Tuberculose. Aide Mémoire 104.

2. PNUD. Évaluation des progrès accomplis en Afrique dans la réalisation des objectifs du Millénaire pour le développement. Rapport OMD 2011.

3. Ministère de la santé et de la prévention du Sénégal (2009) Service national de l'information sanitaire Annuaire statistique Dakar, Sénégal.

4. Ministère de la santé et de la prévention Sénégal / Programme national de lutte contre la tuberculose. Rapport annuel national 2008 des activités de lutte contre la tuberculose. 1 - 17.

5. Programme National de Lutte contre la Tuberculose du Sénégal (2003) Guide de formation pour le personnel de santé impliqué dans la lutte contre la tuberculose dans le district sanitaire au Sénégal. Dakar : PNT.

6. Union Internationale Contre la Tuberculose et les Maladies Respiratoires. Prise en charge de la tuberculose : Guide pour les pays à faibles revenus. Paris: UICTMR, cinquième édition.

7. WHO (2003) Management of tuberculosis, training for health facility staff. A Introduction. Genève: WHO.

8. WHO (2003) Management of tuberculosis, training for health facility staff. B Detect Cases of TB. Genève: WHO.

9. WHO (2003) Management of tuberculosis, training for health facility staff. C Treat TB patients. Genève: WHO.

10. WHO (2003) Management of tuberculosis, training for health facility staff. D: Inform Patients about TB. Genève: WHO.

11. World Health Organization (2004) Global Tuberculosis Control: Surveillance, planning, finances. WHO Report 2004. Geneva: WHO, CDS/TB.

12. World health Organization (1999) Guidelines for the prevention of tuberculosis in health care facilities in resource limited settings. Geneva.

13. Organisation mondlale De La santé (1996) Tuberculosis et vih manuel Clinique. 